REVIEW ARTICLE

\title{
A highly annotated database of genes associated with platinum resistance in cancer
}

\author{
Dongqing Huang ${ }^{1}$, Sara R. Savage ${ }^{2}$, Anna P. Calinawan ${ }^{3}$, Chenwei Lin ${ }^{1}$, Bing Zhang $\mathbb{D}^{2}$, Pei Wang ${ }^{3}$, Timothy K. Starr $\mathbb{D}^{4,5,7}$, \\ Michael J. Birrer ${ }^{6,7}$ and Amanda G. Paulovich (10 ${ }^{1,7 凶}$
}

(c) The Author(s) 2021

Platinum-based chemotherapy, including cisplatin, carboplatin, and oxaliplatin, is prescribed to $10-20 \%$ of all cancer patients. Unfortunately, platinum resistance develops in a significant number of patients and is a determinant of clinical outcome. Extensive research has been conducted to understand and overcome platinum resistance, and mechanisms of resistance can be categorized into several broad biological processes, including (1) regulation of drug entry, exit, accumulation, sequestration, and detoxification, (2) enhanced repair and tolerance of platinum-induced DNA damage, (3) alterations in cell survival pathways, (4) alterations in pleiotropic processes and pathways, and (5) changes in the tumor microenvironment. As a resource to the cancer research community, we provide a comprehensive overview accompanied by a manually curated database of the $>900$ genes/proteins that have been associated with platinum resistance over the last 30 years of literature. The database is annotated with possible pathways through which the curated genes are related to platinum resistance, types of evidence, and hyperlinks to literature sources. The searchable, downloadable database is available online at http://ptrc-ddr.cptac-data-view.org.

Oncogene (2021) 40:6395-6405; https://doi.org/10.1038/s41388-021-02055-2

\section{INTRODUCTION}

Cisplatin, the first platinum-based anti-cancer therapy, was approved by the FDA for treating testicular cancer in 1978, approximately ten years after its cytotoxic function was accidentally discovered by Barnett Rosenberg [1]. In an effort to reduce side effects and increase cytotoxicity, two new platinum compounds, carboplatin and oxaliplatin, were subsequently developed and approved by the FDA. Other formulations have been approved in other countries and novel platinum formulations are currently being developed. It is estimated by the National Cancer Institute that approximately $10-20 \%$ of all cancer patients will receive a platinum drug during the course of their therapy (https://www.cancer.gov/research/progress/discovery/cisplatin).

The main cytotoxic mechanism of platinum is due to the generation of mono adducts and crosslinks in DNA, although other cytotoxic activities have been reported [2] (Fig. 1). The DNA damage caused by platinum results in severe cellular stress, apoptosis, and immune responses that collectively account for the anti-cancer effect of platinum [2]. Tumor response to platinum treatment is complex, heterogeneous, and involves both tumor-intrinsic and tumor-extrinsic activities. Perhaps correspondingly, the development of resistance encompasses multiple mechanisms. Extensive research has been conducted over the last three decades to understand these mechanisms of resistance, which can be broadly categorized into the following biological processes: (1) regulation of drug entry, exit, accumulation, sequestration, and detoxification, (2) enhanced repair and tolerance of platinum induced DNA damage, (3) alterations in cell survival pathways, (4) alterations in pleiotropic processes and pathways, and (5) changes in the tumor microenvironment (Fig. 2). Understanding the complex response to platinum-based therapy will be crucial for developing improved methods for overcoming platinum resistance.

Several excellent reviews have been published covering the topic of platinum resistance [2-4], although no comprehensive, annotated database of genes associated with platinum resistance has been reported. Due to the advent of large-scale genomics and proteomics, the development of annotated sets of functionally related genes/proteins has become increasingly valuable for performing sophisticated analyses, including the use of artificial intelligence. To facilitate a systems biology approach to platinum resistance, we conducted an updated literature review of $>800$ publications covering the last 30 years of research on platinum resistance and developed a highly curated and annotated database of the $>900$ genes/proteins implicated in platinum response (Supplementary Table S1). For each gene, we provide descriptions of the role the gene may play in platinum resistance, hyperlinks to citations that support this role, and a numerical annotation of the type of supporting evidence for each gene, as well as associated pathways. Additionally, we have created a data portal for browsing, searching, and downloading the gene sets and annotations. An overview of the categories of platinum resistance mechanisms represented in the database is provided below.

\footnotetext{
${ }^{1}$ Clinical Research Division, Fred Hutchinson Cancer Research Center, Seattle, WA, USA. ${ }^{2}$ Lester and Sue Smith Breast Center, Baylor College of Medicine, Houston, TX, USA. ${ }^{3}$ Department of Genetics and Genomic Sciences, Icahn School of Medicine at Mount Sinai, New York, NY, USA. ${ }^{4}$ Masonic Cancer Center, University of Minnesota, Minneapolis, MN, USA. ${ }^{5}$ Department of Obstetrics, Gynecology, and Women's Health, University of Minnesota, Minneapolis, MN, USA. ${ }^{6}$ University of Arkansas for Medical Sciences, Little Rock, AR, USA. ${ }^{7}$ These authors jointly supervised this work: Timothy K. Starr, Michael J. Birrer, Amanda G. Paulovich. ${ }^{\bowtie}$ email: apaulovi@fredhutch.org
} 
A B

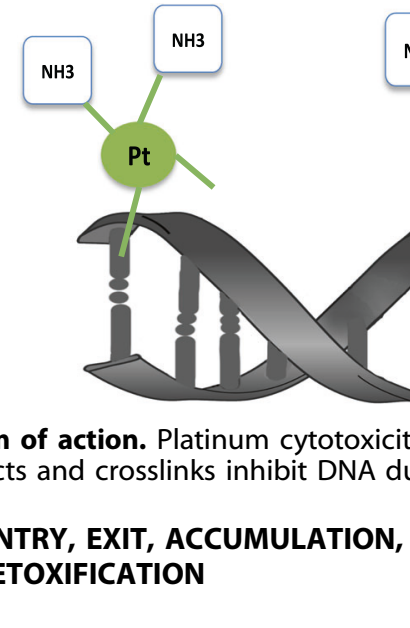
SEQUESTRATION, AND DETOXIFICATION Blocking entry

Cisplatin is actively transported into cells via the plasma membrane sodium pump, copper transporter, and organic cation transporters [5]. Reduced expression of genes encoding the protein constituents of these pumps (SLC31A1/CTR1, SLC22A1/ OCT1, SLC22A2/OCT2, and SLC22A3/OCT3) can lead to platinum resistance (Supplementary Table S1). Endocytosis may be another mechanism of platinum importation, as decreased endocytosis has been associated with platinum resistance [6], while genes involved in regulating endocytosis (e.g., RAB5C or TFRC) are also associated with platinum resistance (Supplementary Table S1).

\section{Enhancing efflux}

In addition to blocking entry, enhanced drug efflux can lead to cisplatin resistance. Two copper exporters, P-type ATPases encoded by ATP7A and ATP7B, modulate cisplatin export [5] and increased expression is associated with cisplatin-resistant tumor cells and poor clinical response in ovarian and endometrial cancer patients (Supplementary Table S1). Many studies have implicated members of the ATP-binding-cassette (ABC) family of transporters, especially the $C$ sub-family consisting of the multidrug resistanceassociated (MRP) genes, including $A B C B 1 / P G P, A B C C 1 / M R P 1$, $A B C C 2 / M R P 2, A B C C 3 / M R P 3, A B C C 4 / M R P 4$, and $A B C C 5 / M R P 5$ in platinum resistance (Supplementary Table $S 1$ ). There is strong evidence that $A B C C 2 / M R P 2$ plays a major role in platinum therapy resistance, since platinum resistant cells have increased expression, and exogenous overexpression induces resistance while reduced expression re-sensitizes cells to platinum [7]. Clinically, high expression levels of both $A B C B 1 / P G P$ and $A B C C 2 / M R P 2$ are associated with platinum resistance in cancer patients (Supplementary Table S1). In addition to increased expression, alterations in glycosylation of two $A B C$ transporters, $A B C C 1 / M R P 1$ and ABCC4/MRP4 (due to reduced levels of glycosylation enzymes GNPTG and MGAT5), result in platinum resistance [8]. Elevated levels of another transporter, MVP/LRP, also correlates with platinum resistance [9].

\section{Sequestration and detoxification}

Cancer cells will actively sequester platinum drugs by generating nucleophilic scavengers, including glutathione (GSH) and metallothioneins, which avidly bind and inactivate platinum drugs. GSH is synthesized in a two-step process requiring glutamate cysteine ligase (encoded by GCLC and GCLM) and glutathione synthase (encoded by GSS) [10]. Once synthesized, the glutathione S-transferase (GST) family of enzymes will catalyze the binding of platinum to GSH [11]. Increased levels of GSH are significantly correlated with platinum resistance in several tumor models; increased levels of many of the enzymes, including GCLC, GSTA1, and GSTP1, are associated with platinum resistance in cell lines;
C 


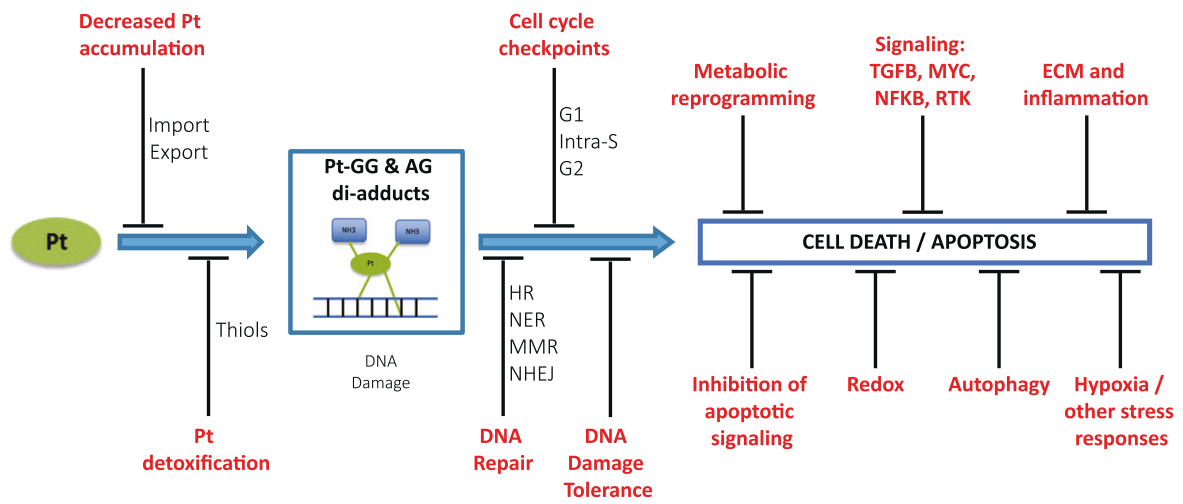

Fig. 2 Mechanisms of platinum resistance. Tumors employ multiple mechanisms to resist platinum-induced cell death. These mechanisms can be categorized as following: (1) Reduced importation and increased exportation, sequestration, and detoxification of platinum (Pt); (2) Enhanced repair and tolerance of platinum induced DNA damage and blockage of cell cycle inhibition; (3) Inhibition of apoptotic signaling, downregulation of reactive oxygen species (ROS), and increased autophagy; (4) Hypoxia and other stress responses (e.g. ER stress response); (5) Metabolic reprogramming; (6) Upregulation of key signaling pathways promoting resistance; and (7) Extracellular mechanisms that alter the extracellular matrix (ECM) and enhance tumor-promoting inflammation.

such as platinum. Downregulation or mutation of genes in the FA pathway results in enhanced sensitivity to platinum drugs [16]. For example, downregulation of FANCA, FANCF, FANCL, or FANCD2 potentiated cisplatin sensitivity in lung cancer cells (Supplementary Table S1). Defects in formation of FANCD2 nuclear foci after cisplatin treatment can be used to indicate cisplatin sensitivity [17] and concomitant overexpression of PARP1, FANCD2, and TP53 predicted increasing resistance to platinum [18].

Homologous recombination and non-homologous end joining (HR and NHEJ). ICLs frequently lead to double strand breaks (DSBs), which require HR or NHEJ for repair. HR-defective (HRD) cancers are often more sensitive to platinum than their HR-proficient counterparts. Two critical components of the HR system are encoded by $B R C A 1$ and $B R C A 2$. Loss of the wild-type allele of either of these two genes is frequently observed in familial breast and ovarian cancers [19] and BRCA1/2-deficient ovarian cancer patients have generally better responses to platinum and are associated with better clinical outcome [20]. Over time, however, the majority of these BRCA1/2-deficient cancers become resistant. In some cases, cisplatin resistance can develop due to secondary mutations that restore $B R C A 1$ or $B R C A 2$ functions [20]. In addition to $B R C A 1 / 2$, other HR proteins also have important prognostic and predictive value for platinum-based therapy. For example, RAD51 foci in the nuclei of cells after cisplatin exposure has been used as an indicator of HRD and platinum sensitivity [21], and high expression levels of MRE11A and RAD50 are independent predictors of platinum resistance in gastric cancer [22]. Furthermore, defects in proteins that regulate HR can also cause HRD and platinum sensitivity. For example, CDK12 phosphorylates the C-terminal domain of RNA polymerase II, regulating transcription of a subset of HR genes including BRCA1 [23]. Somatic CDK12 mutations or chemicals that disable CDK12 function in ovarian cancer cells reduce $B R C A 1$ levels, disrupt $\mathrm{HR}$ repair, and sensitize these cells to platinum [24]. Unlike HR, NHEJ performs DSB repair without requiring a sister chromatid to serve as a template and may compete with HR during DSB repair [25]. Altered activities of NHEJ genes including XRCC5/KU80, XRCC6/KU70, PRKDC/DNA-PKCS, and TP53BP1 can be either negatively or positively associated with platinum resistance, depending on types of cancer cell lines or clinical samples (Supplementary Table S1).

Translesion synthesis (TLS). TLS enables cells to replicate DNA past the adduct to avoid replication fork collapse and death signaling. This increases the tolerance of tumor cells to high levels of platinum-induced DNA adducts and results in platinum resistance.
On the other hand, because TLS can be error-prone, in addition to its role in cell survival upon cisplatin treatment, it also introduces genetic instability, heterogeneity, and platinum-resistant subpopulations [26]. The bypass of platinum adducts by TLS is mediated by a specific group of DNA polymerases including POLH, POLI, POLK, REV1, as well as REV3L/POLZ and MAD2L2/REV7, and increased expression of these genes is correlated with platinum resistance [14]. For example, a high level of POLH is associated with cisplatin resistance in lung and bladder cancer (Supplementary Table S1). REV $3 L / P O L Z$ overexpression confers cisplatin resistance in a glioma cell line, while depletion of this protein diminishes cisplatin resistance (Supplementary Table S1). Clinically, REV $3 L / P O L Z$ and $R E V 1$ germ line mutations were found to be significantly associated with longer overall survival of malignant mesothelioma patients after platinum-based therapy (Supplementary Table S1).

Besides their role in $\mathrm{HR}, B R C A 1$ and $B R C A 2$ also protect stalled replicative forks by preventing degradation of nascent DNA by MRE11A [27]. Knockdown of PAX-interacting protein 1 (PAXIP1) or nucleosome remodeling factor $C H D 4$ restored cisplatin resistance in BRCA2-deficient $\mathrm{B}$ lymphocytes and an ovarian cancer cell line via inhibition of recruitment of MRE11A and diminished degradation of replication forks, independent of $\operatorname{HR}[27,28]$. Moreover, $R A D X$ was found to antagonize the fork-stabilizing activity of $B R C A 2$ and RAD51. Like PAXIP1 and CHD4, loss of RADX restores fork protection and cisplatin resistance to BRCA2-depleted cells without restoring HR [29]. On the other hand, homologous recombination OB-fold protein $(H R O B)$ interacts with RPA1 and $M C M 8 / 9$ to facilitate HR and replication fork progression. Loss of $H R O B$ resulted in cisplatin sensitivity, slower replication fork progression, and increased fork stalling in response to cisplatin [30]. Consistently, BRCA2 mutated ovarian cancers with reduced PAXIP1 or CHD4 expression are associated with shorter progression-free survival and shorter overall survival [27, 28]. Furthermore, in 3D organoid cultures derived from HGSOC patients, replication fork stability was found to correlate with carboplatin sensitivity [31]. Therefore, the status of replication fork stability may be useful for predicting responses to platinum.

Base excision repair (BER). The relationship between BER and platinum resistance is complicated: (1) activity of UNG/UNG1 and $P O L B$ is negatively associated with platinum resistance; (2) activity of FEN1, LIG3, and XRCC1 are positively correlated with platinum resistance; and (3) APEX1 and MUTYH are either positively or negatively associated with platinum resistance, depending on cell context (Supplementary Table S1). These BER proteins have 
multiple other functions related to platinum response in addition to their functions in BER, which could account for the discordant effects. Nevertheless, there are also reports of direct connection between BER and repair of platinum damage [32].

\begin{abstract}
Alterations to cell cycle regulators triggered by DNA damage Maintaining replication competence in the face of DNA damage is a hallmark of cancer and a requirement for platinum resistance. Overcoming cell cycle checkpoints is accomplished via multiple mechanisms, with one of the most important being inactivation of the master cell cycle regulator, TP53. DNA damage results in activation of ATM and ATR, which results in stabilization of the TP53 protein causing increased levels of cell cycle inhibitors, including CDKN1A/p21 ${ }^{C i p}, C D K N 1 B / p 27^{K i p 1}$, and $C D K N 1 C / p 57^{K i p 2}$ [33]. Initiation of cell cycle arrest can have contradictory effects on cells depending on context, resulting in either protection or senescence/apoptosis. Correspondingly, the cellular response to changes in the level of checkpoint inhibitors is complex. For example, both increased and decreased levels of p $21^{\text {Cip }}$ have been associated with increased platinum resistance [34]. Similar effects are seen with another major cell cycle inhibitor CDKN2A/p16 ${ }^{I N K 4 a}$, where decreased levels can result in platinum resistance, while in other cases, result in platinum sensitivity (Supplementary Table S1). Pharmacologic reversal of platinum resistance has been achieved in some preclinical models using inhibitors of the cell cycle regulators CHEK1 and CHEK2 (Supplementary Table S1).
\end{abstract}

\section{ALTERATIONS IN CELL SURVIVAL PATHWAYS Blocking apoptosis}

Both pro-survival and apoptotic signaling pathways are triggered at the same time upon platinum exposure. The final fate of the cell is dependent on the relative intensity and duration of these opposing signals. MAPK pathways, including ERK, p38, and JNK are generally pro-survival, and increased activation of these pathways is generally correlated with increased platinum resistance [35]. Exceptions are numerous, however, due to the pleiotropic effects of MAPK signaling. For example, comparison of a few cisplatinsensitive cell lines and their cisplatin resistant derivatives revealed that p38 and JNK failed to be activated in a sustained fashion in response to cisplatin in the resistant cells [36, 37].

TP53 is a master guardian of the genome and can trigger prosurvival or pro-apoptotic signals depending on cellular context. In most clinical settings, platinum resistance is associated with defective TP53 functions. For example, in testicular germ cell tumors, in which TP53 is predominantly wild type, the patients experience better cure rates to a cisplatin-based regimen than most other adult solid tumor patients [38]. However, in cell lines, the association of cisplatin resistance with mutant TP53 is not clear or even negative. For example, cisplatin resistance sometimes correlates with the presence of wild type TP53 [4]. Moreover, disruption of TP53 function can increase cisplatin sensitivity in some cell lines [39].

Platinum generally triggers apoptosis via the intrinsic pathway initiated at the level of the mitochondria via induction of $B A X$ and $B A K$ through TP53-dependent or MAPK-dependent pathways [40]. Both proapoptotic and antiapoptotic Bcl-2 family members are associated with platinum resistance. For instance, reduced expression or inhibition of the proapoptotic proteins $B A D$ and $B A X$ is associated with poor prognosis in ovarian cancer patients receiving platinum-based chemotherapy (Supplementary Table S1). Overexpression of antiapoptotic proteins such as $B C L 2$, $B C L 2 L 1 / B C L-X L$, and $M C L 1$, on the other hand, negatively correlates with response to cisplatin in ovarian or head and neck squamous cell carcinoma (HNSCC) patients (Supplementary Table S1). In addition to $\mathrm{BCl}-2$, increased levels of members of the inhibitors of apoptosis (IAP) family including BIRC2, BIRC3, BIRC5/survivin, and $X I A P$ are associated with cisplatin resistance and worse clinical outcome in patients of ovarian, esophageal, or head and neck cancer (Supplementary Table S1). Consistent with these findings, $X A F 1$, an inhibitor of XIAP, is associated with a better survival rate in advanced bladder cancer and ovarian cancer patients treated with neoadjuvant chemotherapy (Supplementary Table S1).

In addition to triggering the intrinsic apoptotic pathway, platinum can induce apoptosis through the extrinsic pathway via activation of FAS/FASLG or the DR/caspase-8/caspase-3 pathway [4]. Some components in this pathway are also found to be associated with cisplatin sensitivity in clinical studies. For example, non-small cell lung cancer (NSCLC) patients with higher TNFRSF10B/DR5 expression showed higher response rate to gemcitabine and cisplatin-based chemotherapy [41].

\section{Regulation of reactive oxygen species}

In healthy cells, reactive oxygen species (ROS) are formed during the process of aerobic metabolism and are maintained at low levels. In cancer cells, oxidative stress leads to elevated ROS levels. Platinum therapy increases ROS levels, mostly via the mitochondria [42]. Several mechanisms for platinum-induced ROS have been delineated, including depletion of GSH [2], inhibition of TXNRD1/TrXR1 [43], and other mechanisms involving cytochrome P450 and MNSOD $[44,45]$. Normally, high levels of ROS causes DNA damage, organelle fragmentation, disruption of mitochondria function and depletion of ATP. The cellular response to elevated ROS is complex and involves activated MAPK and TP53 signaling [46]. Cancer cells escape cell death and damage induced by high ROS levels by increasing the production of NADPH and GSH, antioxidant molecules readily used by several ROS-scavenging enzymes to lower ROS levels, such as superoxide dismutases (SODs), catalase (CAT), and glutathione peroxidases (GPX3, GPX4) [47].

$N A D P H$. Elevated levels of G6PD and PGD, the Pentose Phosphate Pathway (PPP) enzymes required for NADPH production, are present in cisplatin-resistant ovarian cancer cell lines, and knockdown of either gene sensitizes cisplatin-resistant cells (Supplementary Table S1). Moreover, ovarian and lung cancer patients with higher $P G D$ levels have worse survival outcomes relative to patients with lower $P G D$ expression (Supplementary Table S1). The transcription factor NFE2L2/NRF2 is a key regulator of oxidative stress and regulates most NADPH-generating enzymes and redox proteins [48]. Upregulation of NFE2L2/NRF2 or downregulation of KEAP1, an E3 ubiquitin ligase that tags NFE2L2/NRF2 for destruction, correlates with platinum resistance in advanced NSCLC (Supplementary Table S1).

GSH. In addition to the role of GSH in platinum detoxification via sequestration and efflux, GSH acts as an antioxidant to neutralize platinum-induced ROS, and high GSH levels are correlated with platinum resistance. Besides the rate-limiting enzyme GCLC, the availability of cysteine, glutamate, and glycine are also important determinants of GSH [49]. Reduced levels of the proteins required to generate these metabolic precursors of GSH, including $P H G D H, C B S$, SLC7A11/xCT, GLS, GLS2, and SLC1A5/ACST2, have been associated with increased platinum sensitivity (Supplementary Table S1).

Aldehydes. Platinum-induced ROS will generate cytotoxic levels of aldehydes via oxidative stress-induced lipid peroxidation [50]. High expression levels of enzymes involved in removing aldehydes, including Aldo-keto reductases (AKR1B10, AKR1C1-3) and Aldehyde dehydrogenases (ALDH1A1, ALDH3A1), were found to be associated with cisplatin resistance in various types of cancer patients including gastrointestinal, ovarian, bladder, NSCLC, and cervical cancer (Supplementary Table S1).

\section{Regulation of autophagy}

Autophagy is a catabolic pathway that involves the sequestration and degradation of damaged organelles and recycles essential 
components in response to stress conditions, including cisplatininduced stresses such as DNA damage, oxidative stress, and ER stress [51]. Autophagy also downregulates proapoptotic proteins and enhances DNA repair [52]. Thus, autophagy reduces stress signaling, maintains cellular homeostasis, and promotes survival upon platinum exposure.

Upregulation of the autophagic pathway has been shown to correlate with platinum resistance in lung cancer cells [53], and genes involved in production of autophagosomes, including ATG5, ATG7, ATG12, ATG14, and BECN1, promote platinum resistance (Supplementary Table S1). Similarly, elevated expression of MAP1LC3A $/ L C 3 A$, a protein required for autophagosome membranes, is associated with platinum resistance in ovarian cancer [54].

\section{ALTERATIONS IN PLEIOTROPIC PROCESSES AND PATHWAYS Hypoxia and the endoplasmic reticulum stress response}

Hypoxia. Cells in solid tumors are exposed to hypoxic conditions, and extensive hypoxia is correlated with platinum resistance and tumor progression [55]. Hypoxic transcriptional programs are mainly activated by the HIF transcription factors but can also be activated by other stress signaling pathways. The response is complex, as HIFs can regulate the transcription of up to $2 \%$ of the human genome [56]. The transcriptional response can result in apoptosis or cell survival, depending on cellular context. HIF1A contributes to platinum resistance indirectly through regulation of the expression of platinum resistance related genes: such as signaling genes MMP9, CXCR4, CXCL8, TGFB3/TGF- $\beta 3$, and VEGFA/ VEGF; DNA repair enzymes PRKDC/DNA-PK, XRCC5/KU70, XRCC6/ $K U 80, X P A, X P C$, and $X P D$; the drug efflux transporters $A B C C 1 / M R P 1$, $A B C G 2 / B C R P$, and MVP/LRP; and EMT transcription factors TWIST1, ZEB1, ZEB2, and TCF3 [56-61] (Supplementary Table S1). HIF1A overexpression is associated with malignancy and poor prognosis in esophageal or head and neck squamous cell carcinoma patients under platinum-based chemotherapy (Supplementary Table S1). Additionally, loss of the E3 ubiquitin ligase $(\mathrm{VHL})$ that tags HIFs for degradation is linked to platinum resistance in renal cancer (Supplementary Table S1).

Endoplasmic reticulum stress and the unfolded protein response. Platinum therapy results in endoplasmic reticulum (ER) stress, which triggers the unfolded protein response (UPR) due to the accumulation of misfolded proteins and disturbances in redox regulation [62]. To maintain cell viability, cancer cells must respond by altered regulation of genes and proteins that participate in this stress response. Heat shock proteins (HSP) are molecular chaperones induced during ER stress and the UPR [63]. Numerous studies have found that increased activities of the HSPB1/HSP27, HSPD1/ HSP60, as well as HSP70, and HSP90 families of HSPs (HSPA1A, HSPA5/GRP78, HSP90AA1, HSP90AB1) are positively correlated with platinum resistance (Supplementary Table S1).

\section{Metabolic reprogramming}

Metabolic reprogramming is an established hallmark of cancer. The Warburg effect was first discovered as a feature of metabolic reprogramming in cancer cells, whereby cancer cells have increased glucose uptake, hyperactivated glycolysis, decreased oxidative phosphorylation (OXPHOS), and the accumulation of lactate, even in the presence of abundant oxygen and functioning mitochondria [64]. Although increased aerobic glycolysis is considered a metabolic hallmark of tumors, its causal relationship with platinum resistance is still controversial. Platinum-resistant tumor cells can either prefer aerobic glycolysis (Warburg-like) or oxidative phosphorylation (OXPHOS-addicted). There are plausible explanations for either metabolic phenotype to promote tumorigenesis and the development of platinum resistance $[65,66]$.

There are reports supporting the role of enhanced aerobic glycolysis in promoting platinum resistance [67]. Conversely, inhibition of aerobic glycolysis can severely deplete ATP and restore platinum sensitivity in cancer cells using aerobic glycolysis [68]. Elevated expression of several key glycolytic enzymes, including SLC2A1/GLUT1, HK2, ENO1, PGK1, PDK1, PDK4, and $P F K F B 3$, was found to correlate with resistance in some cancer cell lines and clinical tissue samples [69] (see also Supplementary Table S1).

On the other hand, the expression levels of proteins related to mitochondrial biogenesis and mitochondrial respiratory chain were found to correlate with platinum resistance in high-OXPHOS cancer cell lines, and inhibition of OXPHOS reduced cisplatinresistance in these cells $[70,71]$.

AMPK is a major regulator of metabolic reprogramming, and its relationship to platinum resistance is also complex. There are reports that activation of AMPK enhances the cytotoxic effects of platinum drugs on cancer cells, but there are also opposing reports that low AMPK activities correlate with better outcomes in resected gastric cancer patients treated with cisplatin-based chemotherapy $[72,73]$.

\section{Translation regulation}

Many cisplatin resistant cell lines express elevated levels of translation factors and ribosomal proteins [74], and many proteins associated with platinum resistance are encoded by mRNAs with complex structures and are highly sensitive to levels of the translation initiation factor EIF4E [75]. Excessive expression of EIF4E is associated with platinum resistance, while knockdown of EIF4E enhances the cytotoxic effects of cisplatin in cell lines and xenograft models [76]. EIF4E is activated by phosphorylation via the AURKA kinase, and overexpression of AURKA correlates with platinum resistance in high grade serous ovarian cancer (HGSOC) patients (Supplementary Table S1).

The mTOR pathway is a central regulator of protein production and can activate EIF4E by phosphorylating the inhibitory protein EIF4EBP 1 and by activating RPS6KB1/p70S6K [77]. Activation of this pathway is strongly linked to platinum resistance [78], and inhibition of MTOR enhanced cisplatin-induced apoptosis [79]. Similarly, the levels of phosphorylated RPS6KB1/p70S6K were elevated in the small cell lung cancer cells that acquired resistance to cisplatin, and activation of RPS6KB1/p70S6K contributes to cisplatin resistance (Supplementary Table S1).

On the other hand, some proteins that downregulate mRNA translation may exert inhibitory effects on the growth and proliferation of tumors and enhance sensitivity to platinum compounds. For example, PDCD4 can suppress protein translation by directly interacting with EIF4A and EIF4G to inhibit the formation of the translation-initiation complex [80]. Overexpression of PDCD4 enhances platinum sensitivity, while knockdown of $P D C D 4$ reduces platinum sensitivity in ovarian cells and in a xenograft model [81].

EIF3A, the largest subunit of the elF3 complex, has peak expression at S-phase and was reported to downregulate the translation of NER proteins XPA, XPC, RAD23B, and RPA2 [82]. Consistent with the role of NER in platinum sensitivity (discussed above), knockdown of EIF3A in nasopharyngeal and ovarian carcinoma cell lines increases cellular resistance to cisplatin. EIF3A expression levels also correlate with better response to platinumbased chemotherapy in lung and ovarian cancer patients (Supplementary Table S1).

\section{Epigenetic alterations}

Epigenetic changes contribute to platinum resistance. For example, elevated expression of SMARCA4, a member of the SWI/SNF chromatin remodeling complex, promotes cisplatin resistance in pancreatic ductal epithelial cells [83], and low expression predicts responsiveness to platinum therapy in NSCLC [84]. Histone $\mathrm{H} 3$ acetylation enhances CD274/PD-L1 expression, which contributes to chemoresistance [85]. High expression of 
CD274/PD-L1 combined with low expression of the histone deacetylase, $H D A C 3$, correlates with platinum resistance in NSCLC [85]. Histone methylation, on the other hand, can either enhance or suppress transcription depending on the context. Knockdown of the histone methyltransferase $K M T 2 B$ reverses platinum sensitivity of $B R C A 1$ or $B R C A 2$ deficient cancer cells by stabilizing replication forks [27], while elevated levels of EZH2, another histone methyltransferase, correlates with poor response to platinum therapy [86].

DNA methylation is generally associated with suppression of transcription, and hypermethylation resulting from aberrant DNA methyltransferase DNMT1 activity has been associated with tumor suppressor gene silencing and chemoresistance in ovarian and other cancer types (Supplementary Table S1). Examples of DNA methylation affecting platinum sensitivity include hypermethylation of the MMR gene $M L H 1$ promoter correlating with platinum resistance in cell lines and predicting poor patient survival $[87,88]$, and methylation of $B R C A 1$ correlating with platinum sensitivity/ response in breast cancer [89].

\section{Alterations in major signaling pathways}

TGF $\beta$ signaling. In general, tumors co-opt TGF $\beta$ signaling to induce metastasis and chemoresistance through promoting angiogenesis, EMT, increased GSH production, a stem cell phenotype, ECM remodeling, and immune escape [90]. Elevated levels of TGF $\beta$ at tumor sites correlate with poor prognosis and treatment resistance in human patients with cancer [91, 92].

TGF $\beta$ is a potent inducer of EMT, which is strongly associated with platinum resistance [93]. Moreover, a gene expression signature associated with TGF $\beta$-activated EMT has been identified in platinum resistant ovarian cancer tissues and can predict platinum resistance [94]. The underlying mechanisms of how TGF $\beta$-activated EMT supports chemoresistance in cancer cells has not been clearly elucidated, but are likely due to increased expression of efflux pumps, DNA repair genes, and effects on major signaling pathways including AKT and TP53 [93, 95]. Many studies have demonstrated that downregulation of EMT-inducing transcription factors including TWIST1, SNAI1/SNAIL, SNAI2/SLUG, and $Z E B 1 / 2$ leads to platinum sensitivity, while upregulation leads to platinum resistance (Supplementary Table S1).

TGF $\beta$ signaling also generates cancer stem cell (CSC) phenotypes, which are linked to cancer progression and treatment resistance. Several studies support the hypothesis that CSCs are responsible for chemoresistance and tumor relapse after conventional chemotherapy removes the bulk population of non-CSCs $[96,97]$. Multiple markers of the CSC phenotype (e.g., CD44, CD24, ALDH1A1, NANOG) are found to be correlated with platinum resistance in cancer patients of various types (Supplementary Table S1).

MYC signaling. In human ovarian tumors, amplification of $M Y C$ is common $[98,99]$, and high expression of MYC is associated with platinum resistance in ovarian cancer [100]. MYC promotes platinum resistance mainly through transactivation of a broad range of genes that drive glucose metabolism, glutamine metabolism, one carbon metabolism, fatty acid synthesis, oxidative phosphorylation, nucleotide synthesis, and protein biogenesis, which results in increased cell survival and proliferation [101]. For example, MYC promotes glutamine import by directly inducing the expression of key glutamine transporters SLC7A5, SLC1A5, and GLS [102] and it is well documented that increased utilization of glutamine induces platinum resistance [103]. The mechanism is not entirely clear, but likely includes increased nucleotide and glutathione synthesis [49, 103]. Myc signaling also results in protecting cells from platinum-induced ROS toxicity by activating a mitochondrial methyl transferase (SHMT2), which results in elevated NADPH [104], and by activating $N F E 2 L 2 / N R F$, a master transcription factor regulating ROSdetoxifying enzymes [48].
NFKB signaling. Another well-known transcription factor complex that promotes cancer cell survival is nuclear factor kappa-lightchain-enhancer of activated B cells (NFKB), a family of transcription factors constituted by dimers of different combinations of 5 proteins sharing structural homology (NFKB1, NFKB2, RELA, RELB, and REL) [105]. Higher levels of NFKB correlate with platinum resistance and poor outcome in ovarian cancer [106]. Interestingly, cisplatin itself likely causes upregulation of NFKB via activation of the DDR, resulting in ATM-mediated phosphorylation of the NFKB inhibitors, CHUK/IKKa and IKBKB/IKKB [107]. Mechanistically, NFKB promotes survival by activating anti-apoptotic genes, including TRAF1, TRAF2, BIRC2/CIAP1, BIRC3/CIAP2, XIAP, BCL2A1/BIf/A1, $B C L 2 L 1 / B C l-X L$, and CFLAR/FLIP $[108,109]$, as well as detoxifying and redox genes such as NQO1, SOD1, and SOD2 [110]. NFKB also triggers inflammatory responses via induction of various proinflammatory genes, including those encoding cytokines [111], which are associated with platinum resistance (see Section $5 b$ ).

Receptor tyrosine kinase signaling. Receptor tyrosine kinase (RTK) signaling triggers cell growth and blocks apoptosis, enhancing cancer cell survival and proliferation in the presence of platinum and other anti-cancer drugs $[112,113]$. Many studies have specifically implicated the PI3K/Akt and the Ras/MAPK signaling pathways in the induction of platinum resistance. For example, overexpression of the EGFR family member ERBB2/HER2/NEU, which activates the $\mathrm{PI} 3 \mathrm{~K} / \mathrm{Akt}$ pathway, is associated with platinum resistance in ovarian, NSCLC, and HNSCC cancer patients (Supplementary Table S1). In support of this observation, pharmacological targeting of MTOR, a key downstream signaling kinase in the pathway, can re-sensitize tumors to platinum drugs $[78$, 79]. Both the PI3K/Akt and Ras/MAPK signaling will phosphorylate the proapoptotic protein $B A D$, causing inactivation due to cytoplasmic sequestration, which leads to enhanced platinum resistance by blocking apoptosis [114]. Similarly, both AKT and MAPK signaling result in activation of the AP1 transcription factor complex (FOS and $J U N$ ), and overexpression of these genes are associated with platinum resistance, while downregulation re-sensitizes tumor cells to platinum [115] (see also Supplementary Table S1).

Activation of the Ras/MAPK pathway via activating mutations in RAS or overexpression of RAS confers resistance to platinum [115], while downstream of RAS, high expression of MAP2K1/MEK 1 is associated with platinum resistance and correlates with reduced progression free survival of patients [116].

\section{CHANGES IN THE TUMOR MICROENVIRONMENT Extracellular matrix remodeling}

The effects of the extracellular matrix (ECM) on cells are primarily mediated by integrins, a family of cell surface receptors that attach cells to the matrix and trigger signal transduction [117]. Alterations in the ECM can initiate integrin signaling and confer platinum resistance to cancer cells. For example, collagen and fibronectin in the ECM can synergistically activate PI3K/Akt signaling, causing increased cancer cell resistance to cisplatin. Increased levels of one collagen variant, COL1A1, enhances cisplatin resistance in liver and ovarian cancer cells via upregulation of MAPK and mTOR pathways (Supplementary Table S1). Another variant, COL11A1, activates PI3K/Akt and NFKB pathways to exert anti-apoptotic effects that are associated with chemoresistance [118]; high expression of this variant was significantly associated with platinum resistance and clinical outcome in ovarian cancer (Supplementary Table S1). On the other hand, Akt signaling can be activated by upregulation of fibronectin on stroma cells and contributes to platinum resistance in ovarian cancer cells [119], and high levels of FN1 in serum have positive correlation with recurrence and shorter progression free survival in ovarian cancer patients under platinum-based therapy [120]. 
Some of the integrins responsible for these resistance signals have been identified, including ITGA5, ITGA6, ITGB1, and ITGB6, where elevated levels are correlated with reduced overall survival and cisplatin resistance in human hilar cholangiocarcinoma patients and ovarian cancer (Supplementary Table S1). Downstream of integrin signaling, the focal adhesion kinase PTK2/FAK, was also found to drive platinum resistance by promoting survival [121]. Changes in the ECM are instigated by both cancer cells and cancer-associated fibroblasts. For example, ovarian cancer associated stroma cells are able to induce platinum resistance via induction of the fibronectin/Akt signaling pathway [119].

\section{Immune system induced inflammation}

Tumor-promoting chronic inflammation leads to an innate immune response that promotes cancer development and progression and can contribute to platinum resistance [122]. Activation of the innate immune response results in the production of cytokines, including interleukins, interferons and tumor necrosis factor, which have all been associated with platinum resistance [123]. Nonetheless, the effects of cytokines are complex and often context-dependent, in some cases causing increased platinum resistance, while in other cases sensitizing tumors to platinum therapy.

Multiple lines of evidence indicate that TNF/TNFA expression enhances cisplatin resistance in cell lines, and elevated expression is associated with poor patient outcome (Supplementary Table S1). Similarly, high expression levels of many interleukins including IL6, IL7, CXCL8/IL8, IL11, and ILITA/IL17 are correlated with increased platinum resistance or poor clinical outcome in several types of cancer (Supplementary Table S1). The JAK/STAT pathway, commonly activated by these cytokines, stimulates STAT transcription factors including STAT1 and STAT3 [124]. While STAT1 activity could indicate either platinum response or resistance, high levels of STAT3 is generally associated with platinum resistance (Supplementary Table S1). Plausible mechanisms for STAT3enhanced resistance include upregulation of the anti-apoptotic proteins BCL2 and BIRC5/Survivin, the oncogene MYC, EMT genes [125], and activation of ATF6, resulting in ER stress response and autophagy [126].

On the other hand, when IFNG/Interferon- $\gamma$ is used as a treatment, it can enhance the therapeutic effect of cisplatin in ovarian cancer, as shown by reduced tumor volume and prolonged progression-free survival [127]. Supporting the positive effect of IFNG, induction of the IFNG/STAT1 pathway correlates with improved treatment response in ER negative breast cancer in a mouse model [128]. Moreover, contrary to the harmful effects of TNF cited above, when TNF is targeted to cancer endothelial cells in refractory NSCLC patients, there has been evidence of enhanced cisplatin toxicity [129]. Similarly, administration of ILIA, IL7, or IL24 enhanced the anti-tumor efficacy of cisplatin in lung cancer (Supplementary Table S1).

Other platinum resistance mechanisms induced by the innate immune response include upregulation of the AP1 oncogenes (FOS and JUN) [130], upregulation of pro-survival genes including HSP7O and HMOX1/HO-1 [131, 132], increased drug efflux [133], and activation of the EMT program [97].

\section{DATABASE OF GENES ASSOCIATED WITH PLATINUM RESISTANCE}

The accompanying gene table (Supplementary Table S1) was generated following an extensive literature search. Publications reporting on platinum resistance were identified in Pubmed (The MEDLINE database) using the python NLTK package with the following search keywords: ("platinum" OR "cisplatin") AND ("resistance" OR "sensitivity") AND "cancer" AND (Date of publication: 1988-2020) along with all human gene symbols. Inclusion was also manually curated based on the expertise of our group. Publications were selected only if they contained genes that (1) showed differential expression between platinum resistant and sensitive cancer cells (or tissues); and (2) whose gene knockdown, mutation, or overexpression resulted in changes in platinum sensitivity. Our final database contains 1,628 unique PMID citations.

Our database includes the following information from the literature review: gene and protein identifiers including the $\mathrm{NCBI}$ Gene ID, Uniprot protein ID, HUGO gene symbol, and alternate IDs; manually curated functional annotations related to platinum resistance based on the literature review, with hyperlinked citations; and manually curated annotations indicating whether gene expression is increased or decreased during development of platinum resistance and pathways associated with the gene. We added a score annotation describing the strength of evidence supporting the gene's role in platinum resistance (Supplementary Table S2, Fig. 3A). This score may be used as a threshold to filter the table based on the level of evidence (cell line, animal model, and/or human tissue). To complement our manual pathway annotation, we performed an over-representation analysis to identify enriched Gene Ontology (GO) Biological Processes using WebGestalt [134]. Top enriched functions included apoptosis, oxidative stress, and DNA repair (Fig. 3B, full results in Supplementary Table S3). Finally, targets of FDA approved drugs were annotated [135].

A searchable, filterable, and downloadable version of the table is available online at http://ptrc-ddr.cptac-data-view.org. This web application includes an interactive visualization of the number of genes assigned to each putative platinum resistance mechanism pathway.

\section{CONCLUDING REMARKS}

Based on 30 years of literature, multiple mechanisms are exploited by cancer cells to evade the cytotoxic effects of platinum therapy. Experimental evidence from the platinum-resistant PEO4 ovarian cancer cell line serves as a striking example of the multifactorial nature of platinum resistance. Multiple mechanisms of platinum resistance have been implicated in PEO4, including: a) restoration of DDR via a BRCA2 reversion mutation [136]; b) alterations in histone methylation via overexpression of Histone-lysine $\mathrm{N}$ methyltransferase EZH2 [86]; c) activation of HIF1A [137]; d) activation of TGF $\beta$ signaling [138]; e) inhibition of pro-apoptotic $\mathrm{Bcl} 2$ family proteins [139]; and $\mathrm{f}$ ) activation of transcription factor STAT1 by deacetylase HDAC4 [140]. Clonal heterogeneity within tumors exacerbates this phenomenon, as platinum resistance is often driven by pre-existing resistant subclones co-inhabiting a single tumor mass and interspersed with sensitive cancer cell clones [141]. This multifaceted nature of resistance poses a major hurdle for developing effective therapeutic approaches targeting platinum resistant tumors, as well as predictive biomarkers of platinum response. Identifying and targeting dominant signaling pathways and networks of proteins that drive resistance will be important. One promising approach is to use the rapidly expanding omics datasets created by next generation technologies. To effectively interpret these large datasets, it will be necessary to develop new bioinformatic algorithms using systems biology and artificial intelligence. The gene list and gene matrix transposed (GMT) files, as well as the online data portal, provided with this review can be utilized to add knowledge-based annotations to these datasets.

Further confounding our ability to therapeutically target mechanisms of platinum resistance is that specific mechanisms can be context dependent. For example, upregulation of MYC promotes platinum resistance through activation of a broad range of genes that promote proliferation, redox balance, and energy generation. However, MYC is also implicated in platinum-induced p53 mediated apoptosis [142]. While high expression of MYC is 


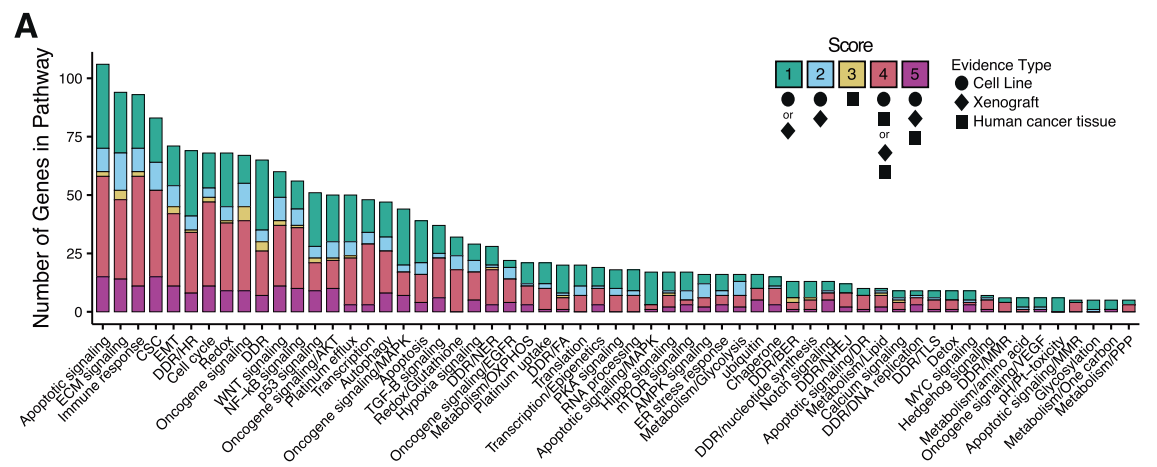

$\mathbf{B}$

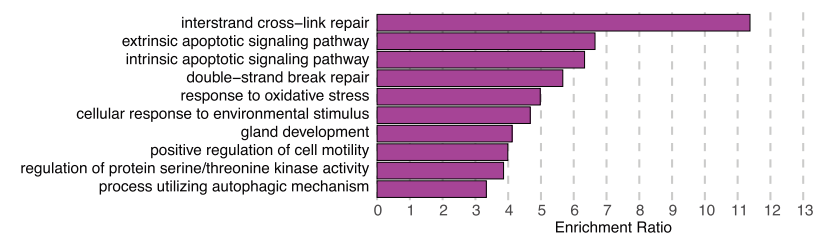

Fig. 3 Pathway annotation of genes. A Number of genes (in Supplementary Table S1) at each level of evidence assigned to each putative platinum resistance mechanism pathway. Genes are assigned evidence scores based on experiments from cell lines, xenograft models, and/or human cancer tissue. Only pathways with at least five genes are shown. B Top GO biological process term enrichment of genes in Supplementary Table S1.

associated with platinum resistance in TP53 mutant ovarian cancer $[86,100]$, the opposite is seen in ER-positive breast cancer, where high expression is associated with platinum sensitivity [143]. The cell cycle inhibitor, CHEK2, serves as another example. In some ovarian cancer cell lines, the cell cycle checkpoint and DDR functions of CHEK2 causes increased resistance to cisplatin [144]. However, in esophageal squamous cell carcinomas and some ovarian cancers, higher expression of CHEK2 is associated with favorable response to cisplatin-based therapy [145, 146]. The complex response to oxidative damage induced by platinum therapy normally results in elevated ROS levels, and cancer cells with lower ROS levels are generally less susceptible to platinuminduced oxidative damage [47] and, therefore, are associated with platinum resistance. In these tumor cells, glycolytic metabolism could support the energetic demand that allows cellular proliferation and tumor expansion [64], while downregulation of OXPHOS diminishes ROS production and reduces the threshold for apoptosis induced by platinum [147]. However, in other platinumresistant cancer cells, which often have increased endogenous oxygen consumption and mitochondrial activity, higher sublethal ROS levels have direct causative effects on platinum resistance through activation of antioxidation system and proliferative signaling $[43,133]$. For example, increased expression of the antioxidant thioredoxin-1 (TXN) is associated with lower ROS and decreased cisplatin-resistance in a lung cancer cell line [43]. In contrast, upregulation of TXN is associated with an increased resistance to cisplatin in other cell lines [148, 149]. These results demonstrate the importance of cellular context and will need to be considered when developing therapies targeting platinum resistance mechanisms.

Platinum drugs are effective anticancer drugs used for treatment of epithelial neoplasms. Unfortunately, in a large number of cases, tumors are able to subvert the cytotoxic effects of platinum, resulting in platinum resistance and cancer mortality. Here, we have reviewed the evidence supporting the hypothesis that a large number of genes can contribute to platinum resistance either directly or indirectly. We also provide a manually annotated database of these genes that can be incorporated into large-scale omics analyses to facilitate development of therapies aimed at overcoming platinum resistance.

\section{REFERENCES}

1. Rosenberg B, Vancamp L, Krigas T. Inhibition of cell division in escherichia coli by electrolysis products from a platinum electrode. Nature. 1965;205:698-9.

2. Galluzzi L, Senovilla L, Vitale I, Michels J, Martins I, Kepp O, et al. Molecular mechanisms of cisplatin resistance. Oncogene. 2012;31:1869-83.

3. Rottenberg S, Disler C, Perego P. The rediscovery of platinum-based cancer therapy. Nat Rev Cancer. 2021;21:37-50.

4. Siddik ZH. Cisplatin: mode of cytotoxic action and molecular basis of resistance. Oncogene. 2003;22:7265-79.

5. Ciarimboli G. Membrane transporters as mediators of Cisplatin effects and side effects. Sci (Cairo). 2012;2012:473829.

6. Chauhan SS, Liang XJ, Su AW, Pai-Panandiker A, Shen DW, Hanover JA, et al. Reduced endocytosis and altered lysosome function in cisplatin-resistant cell lines. Br J Cancer. 2003;88:1327-34.

7. Baiceanu E, Crisan G, Loghin F, Falson P. Modulators of the human ABCC2: hope from natural sources? Future Med Chem. 2015;7:2041-63.

8. Beretta GL, Benedetti V, Cossa G, Assaraf YG, Bram E, Gatti L, et al. Increased levels and defective glycosylation of MRPs in ovarian carcinoma cells resistant to oxaliplatin. Biochem Pharm. 2010;79:1108-17.

9. Izquierdo MA, Scheffer GL, Schroeijers AB, de Jong MC, Scheper RJ. Vault-related resistance to anticancer drugs determined by the expression of the major vault protein LRP. Cytotechnology. 1998;27:137-48.

10. Lu SC. Glutathione synthesis. Biochim Biophys Acta. 2013;1830:3143-53.

11. Bousova I, Skalova L. Inhibition and induction of glutathione S-transferases by flavonoids: possible pharmacological and toxicological consequences. Drug Metab Rev. 2012;44:267-86.

12. Borst $P$, Evers $R$, Kool M, Wijnholds J. A family of drug transporters: the multidrug resistance-associated proteins. J Natl Cancer Inst. 2000;92:1295-302.

13. Chaney SG, Campbell SL, Bassett E, Wu Y. Recognition and processing of cisplatin- and oxaliplatin-DNA adducts. Crit Rev Oncol Hematol. 2005;53:3-11.

14. Rocha CRR, Silva MM, Quinet A, Cabral-Neto JB, Menck CFM. DNA repair pathways and cisplatin resistance: an intimate relationship. Clin (Sao Paulo). 2018;73:e478s.

15. Kirschner K, Melton DW. Multiple roles of the ERCC1-XPF endonuclease in DNA repair and resistance to anticancer drugs. Anticancer Res. 2010;30:3223-32.

16. Yao CJ, Du W, Zhang Q, Zhang F, Zeng F, Chen FP. Fanconi anemia pathway-the way of DNA interstrand cross-link repair. Pharmazie. 2013;68:5-11.

17. Burkitt $K$, Ljungman $M$. Phenylbutyrate interferes with the Fanconi anemia and BRCA pathway and sensitizes head and neck cancer cells to cisplatin. Mol Cancer. 2008;7:24.

18. Wysham WZ, Mhawech-Fauceglia P, Li H, Hays L, Syriac S, Skrepnik T, et al. BRCAness profile of sporadic ovarian cancer predicts disease recurrence. PLoS One. 2012;7:e30042.

19. Narod SA, Foulkes WD. BRCA1 and BRCA2: 1994 and beyond. Nat Rev Cancer. 2004;4:665-76. 
20. Dhillon KK, Swisher EM, Taniguchi T. Secondary mutations of BRCA1/2 and drug resistance. Cancer Sci. 2011;102:663-9.

21. Adam-Zahir S, Plowman PN, Bourton EC, Sharif F, Parris CN. Increased gamma$\mathrm{H} 2 \mathrm{AX}$ and Rad51 DNA repair biomarker expression in human cell lines resistant to the chemotherapeutic agents nitrogen mustard and cisplatin. Chemotherapy. 2014:60:310-20.

22. Altan B, Yokobori T, Ide M, Bai T, Yanoma T, Kimura A, et al. High expression of MRE11-RAD50-NBS1 is associated with poor prognosis and chemoresistance in gastric cancer. Anticancer Res. 2016;36:5237-47.

23. Dubbury SJ, Boutz PL, Sharp PA. CDK12 regulates DNA repair genes by suppressing intronic polyadenylation. Nature. 2018;564:141-5.

24. Quereda V, Bayle S, Vena F, Frydman SM, Monastyrskyi A, Roush WR, et al. Therapeutic targeting of CDK12/CDK13 in triple-negative breast cancer. Cancer Cell. 2019;36:545-58.e547.

25. Dev H, Chiang TW, Lescale C, de Krijger I, Martin AG, Pilger D, et al. Shieldin complex promotes DNA end-joining and counters homologous recombination in BRCA1-null cells. Nat Cell Biol. 2018;20:954-65.

26. Zhang $\mathrm{H}$. Mechanisms of mutagenesis induced by DNA lesions: multiple factors affect mutations in translesion DNA synthesis. Crit Rev Biochem Mol Biol. 2020;55:219-51.

27. Ray Chaudhuri A, Callen E, Ding X, Gogola E, Duarte AA, Lee JE, et al. Replication fork stability confers chemoresistance in BRCA-deficient cells. Nature. 2016;535:382-7.

28. Guillemette S, Serra RW, Peng M, Hayes JA, Konstantinopoulos PA, Green MR, et al. Resistance to therapy in BRCA2 mutant cells due to loss of the nucleosome remodeling factor CHD4. Genes Dev. 2015;29:489-94.

29. Dungrawala H, Bhat KP, Le Meur R, Chazin WJ, Ding X, Sharan SK, et al. RADX promotes genome stability and modulates chemosensitivity by regulating RAD51 at Replication Forks. Mol Cell. 2017;67:374-86.e375.

30. Hustedt N, Saito Y, Zimmermann M, Alvarez-Quilon A, Setiaputra D, Adam S, et al. Control of homologous recombination by the HROB-MCM8-MCM9 pathway. Genes Dev. 2019;33:1397-415.

31. Hill SJ, Decker B, Roberts EA, Horowitz NS, Muto MG, Worley MJ Jr., et al. Prediction of DNA repair inhibitor response in short-term patient-derived ovarian cancer organoids. Cancer Disco. 2018;8:1404-21.

32. Sawant A, Floyd AM, Dangeti M, Lei W, Sobol RW, Patrick SM. Differential role of base excision repair proteins in mediating cisplatin cytotoxicity. DNA Repair (Amst). 2017;51:46-59.

33. Lim S, Kaldis P. Cdks, cyclins and CKls: roles beyond cell cycle regulation. Development. 2013;140:3079-93.

34. Georgakilas AG, Martin OA, Bonner WM. p21: A Two-Faced Genome Guardian. Trends Mol Med. 2017;23:310-9.

35. Lee S, Rauch J, Kolch W. Targeting MAPK Signaling in Cancer: Mechanisms of Drug Resistance and Sensitivity. Int J Mol Sci. 2020;21:1102.

36. Brozovic A, Fritz G, Christmann M, Zisowsky J, Jaehde U, Osmak M, et al. Longterm activation of SAPK/JNK, p38 kinase and fas-L expression by cisplatin is attenuated in human carcinoma cells that acquired drug resistance. Int J Cancer. 2004;112:974-85.

37. Mansouri A, Ridgway LD, Korapati AL, Zhang Q, Tian L, Wang Y, et al. Sustained activation of JNK/p38 MAPK pathways in response to cisplatin leads to Fas ligand induction and cell death in ovarian carcinoma cells. J Biol Chem. 2003;278:19245-56.

38. Schmidtova S, Kalavska K, Kucerova L. Molecular mechanisms of cisplatin chemoresistance and its circumventing in testicular germ cell tumors. Curr Oncol Rep. 2018;20:88.

39. Fan S, Smith ML, Rivet DJ 2nd, Duba D, Zhan Q, Kohn KW, et al. Disruption of p53 function sensitizes breast cancer MCF-7 cells to cisplatin and pentoxifylline. Cancer Res. 1995;55:1649-54

40. Tajeddine N, Galluzzi L, Kepp O, Hangen E, Morselli E, Senovilla L, et al. Hierarchical involvement of Bak, VDAC1 and Bax in cisplatin-induced cell death. Oncogene. 2008;27:4221-32.

41. Han JY, Hong EK, Choi BG, Park JN, Kim KW, Kang JH, et al. Death receptor 5 and $\mathrm{Bcl}-2$ protein expression as predictors of tumor response to gemcitabine and cisplatin in patients with advanced non-small-cell lung cancer. Med Oncol. 2003;20:355-62.

42. Kleih M, Bopple K, Dong M, Gaissler A, Heine S, Olayioye MA, et al. Direct impact of cisplatin on mitochondria induces ROS production that dictates cell fate of ovarian cancer cells. Cell Death Dis. 2019;10:851.

43. Wangpaichitr M, Sullivan EJ, Theodoropoulos G, Wu C, You M, Feun LG, et al. The relationship of thioredoxin-1 and cisplatin resistance: its impact on ROS and oxidative metabolism in lung cancer cells. Mol Cancer Ther. 2012;11:604-15.

44. Yuan $\mathrm{Y}$, Wang $\mathrm{H}, \mathrm{Wu} \mathrm{Y}$, Zhang B, Wang N, Mao $\mathrm{H}$, et al. P53 Contributes to Cisplatin Induced Renal Oxidative Damage via Regulating P66shc and MnSOD. Cell Physiol Biochem. 2015;37:1240-56.

45. Liu H, Baliga R. Cytochrome P450 2E1 null mice provide novel protection against cisplatin-induced nephrotoxicity and apoptosis. Kidney Int. 2003;63:1687-96.
46. Pan JS, Hong MZ, Ren JL. Reactive oxygen species: a double-edged sword in oncogenesis. World J Gastroenterol. 2009;15:1702-7.

47. Panieri E, Santoro MM. ROS homeostasis and metabolism: a dangerous liason in cancer cells. Cell Death Dis. 2016;7:e2253.

48. Vomund S, Schafer A, Parnham MJ, Brune B, von Knethen A. Nrf2, the master regulator of anti-oxidative responses. Int J Mol Sci. 2017;18:2772.

49. Gorrini C, Harris IS, Mak TW. Modulation of oxidative stress as an anticancer strategy. Nat Rev Drug Disco. 2013;12:931-47.

50. Su Y, Zhao B, Zhou L, Zhang Z, Shen Y, Lv H, et al. Ferroptosis, a novel pharmacological mechanism of anti-cancer drugs. Cancer Lett. 2020;483:127-36.

51. Kroemer G, Marino G, Levine B. Autophagy and the integrated stress response. Mol Cell. 2010;40:280-93.

52. Zhang D, Tang B, Xie X, Xiao YF, Yang SM, Zhang JW. The interplay between DNA repair and autophagy in cancer therapy. Cancer Biol Ther. 2015;16:1005-13.

53. Ren JH, He WS, Nong L, Zhu QY, Hu K, Zhang RG, et al. Acquired cisplatin resistance in human lung adenocarcinoma cells is associated with enhanced autophagy. Cancer Biother Radiopharm. 2010;25:75-80.

54. Miyamoto $M$, Takano $M$, Aoyama $T$, Soyama $H$, Yoshikawa $T$, Tsuda $H$, et al. Inhibition of autophagy protein LC3A as a therapeutic target in ovarian clear cell carcinomas. J Gynecol Oncol. 2017;28:e33.

55. Gaustad JV, Hauge A, Wegner CS, Simonsen TG, Lund KV, Hansem LMK, et al. DCE-MRI of tumor hypoxia and hypoxia-associated aggressiveness. Cancers (Basel). 2020;12:1979.

56. Semenza GL. Hypoxia-inducible factors: mediators of cancer progression and targets for cancer therapy. Trends Pharm Sci. 2012;33:207-14.

57. Balamurugan K. HIF-1 at the crossroads of hypoxia, inflammation, and cancer. Int J Cancer. 2016;138:1058-66.

58. Hong SS, Lee H, Kim KW. HIF-1alpha: a valid therapeutic target for tumor therapy. Cancer Res Treat. 2004;36:343-53.

59. Rezvani HR, Mahfouf W, Ali N, Chemin C, Ged C, Kim AL, et al. Hypoxia-inducible factor-1alpha regulates the expression of nucleotide excision repair proteins in keratinocytes. Nucleic Acids Res. 2010;38:797-809.

60. Rohwer N, Zasada C, Kempa S, Cramer T. The growing complexity of HIF1alpha's role in tumorigenesis: DNA repair and beyond. Oncogene. 2013;32:3569-76.

61. Roy S, Kumaravel S, Sharma A, Duran CL, Bayless KJ, Chakraborty S. Hypoxic tumor microenvironment: implications for cancer therapy. Exp Biol Med (Maywood). 2020;245:1073-86.

62. Mandic A, Hansson J, Linder S, Shoshan MC. Cisplatin induces endoplasmic reticulum stress and nucleus-independent apoptotic signaling. J Biol Chem. 2003;278:9100-6.

63. Jego G, Hazoume A, Seigneuric R, Garrido C. Targeting heat shock proteins in cancer. Cancer Lett. 2013;332:275-85.

64. Liberti MV, Locasale JW. The Warburg effect: how does it benefit cancer cells? Trends Biochem Sci. 2016;41:211-8.

65. Ma L, Zong X. Metabolic symbiosis in chemoresistance: refocusing the role of aerobic glycolysis. Front Oncol. 2020;10:5.

66. Jose C, Bellance N, Rossignol R. Choosing between glycolysis and oxidative phosphorylation: a tumor's dilemma? Biochim Biophys Acta. 2011;1807:552-61.

67. Chakraborty PK, Mustafi SB, Xiong X, Dwivedi SKD, Nesin V, Saha S, et al. MICU1 drives glycolysis and chemoresistance in ovarian cancer. Nat Commun. 2017;8:14634.

68. Fan $T$, Sun $G$, Sun $X$, Zhao $L$, Zhong $R$, Peng $Y$. Tumor energy metabolism and potential of 3-bromopyruvate as an inhibitor of aerobic glycolysis: implications in tumor treatment. Cancers (Basel). 2019;11:317.

69. Varghese E, Samuel SM, Liskova A, Samec M, Kubatka P, Busselberg D. Targeting glucose metabolism to overcome resistance to anticancer chemotherapy in breast cancer. Cancers (Basel). 2020;12:2252.

70. Cruz-Bermudez A, Laza-Briviesca R, Vicente-Blanco RJ, Garcia-Grande A, Coronado MJ, Laine-Menendez $S$, et al. Cisplatin resistance involves a metabolic reprogramming through ROS and PGC-1alpha in NSCLC which can be overcome by OXPHOS inhibition. Free Radic Biol Med. 2019;135:167-81.

71. Dar S, Chhina J, Mert I, Chitale D, Buekers T, Kaur H, et al. Bioenergetic adaptations in chemoresistant ovarian cancer cells. Sci Rep. 2017;7:8760.

72. Yung MM, Ngan HY, Chan DW. Targeting AMPK signaling in combating ovarian cancers: opportunities and challenges. Acta Biochim Biophys Sin (Shanghai). 2016;48:301-17.

73. Kang BW, Jeong JY, Chae YS, Lee SJ, Lee YJ, Choi JY, et al. Phosphorylated AMPactivated protein kinase expression associated with prognosis for patients with gastric cancer treated with cisplatin-based adjuvant chemotherapy. Cancer Chemother Pharm. 2012;70:735-41.

74. Wu C, Wangpaichitr M, Feun L, Kuo MT, Robles C, Lampidis T, et al. Overcoming cisplatin resistance by mTOR inhibitor in lung cancer. Mol Cancer. 2005;4:25.

75. Graff JR, Konicek BW, Carter JH, Marcusson EG. Targeting the eukaryotic translation initiation factor 4E for cancer therapy. Cancer Res. 2008;68:631-4. 
76. Liu T, Li R, Zhao H, Deng J, Long Y, Shuai MT, et al. elF4E promotes tumorigenesis and modulates chemosensitivity to cisplatin in esophageal squamous cell carcinoma. Oncotarget. 2016;7:66851-64.

77. Inoki K, Ouyang H, Li Y, Guan KL. Signaling by target of rapamycin proteins in cell growth control. Microbiol Mol Biol Rev. 2005;69:79-100.

78. Marquard FE, Jucker M. PI3K/AKT/mTOR signaling as a molecular target in head and neck cancer. Biochem Pharm. 2020;172:113729.

79. Musa F, Alard A, David-West G, Curtin JP, Blank SV, Schneider RJ. Dual mTORC1/ 2 inhibition as a novel strategy for the resensitization and treatment of platinum-resistant ovarian cancer. Mol Cancer Ther. 2016;15:1557-67.

80. Biyanee A, Singh P, Klempnauer KH. Translation, Pdcd4 and elF4A. Oncoscience. 2015;2:731-2.

81. Zhang $X$, Wang $X$, Song $X$, Liu C, Shi $Y$, Wang $Y$, et al. Programmed cell death 4 enhances chemosensitivity of ovarian cancer cells by activating death receptor pathway in vitro and in vivo. Cancer Sci. 2010;101:2163-70.

82. Liu RY, Dong Z, Liu J, Yin JY, Zhou L, Wu X, et al. Role of elF3a in regulating cisplatin sensitivity and in translational control of nucleotide excision repair of nasopharyngeal carcinoma. Oncogene. 2011;30:4814-23.

83. Davidson J, Shen Z, Gong X, Pollack JR. SWI/SNF aberrations sensitize pancreatic cancer cells to DNA crosslinking agents. Oncotarget. 2018;9:9608-17.

84. Bell EH, Chakraborty AR, Mo X, Liu Z, Shilo K, Kirste S, et al. SMARCA4/BRG1 is a novel prognostic biomarker predictive of cisplatin-based chemotherapy outcomes in resected non-small cell lung cancer. Clin Cancer Res. 2016;22:2396-404.

85. Wang $\mathrm{H}, \mathrm{Fu} \mathrm{C}$, Du J, Wang $\mathrm{H}, \mathrm{He} \mathrm{R}$, Yin $\mathrm{X}$, et al. Enhanced histone $\mathrm{H} 3$ acetylation of the PD-L1 promoter via the COP1/C-Jun/HDAC3 axis is required for PD-L1 expression in drug-resistant cancer cells. J Exp Clin Cancer Res. 2020;39:29.

86. Sun J, Cai X, Yung MM, Zhou W, Li J, Zhang Y, et al. miR-137 mediates the functional link between c-Myc and $\mathrm{EZH} 2$ that regulates cisplatin resistance in ovarian cancer. Oncogene. 2019;38:564-80.

87. Gifford G, Paul J, Vasey PA, Kaye SB, Brown R. The acquisition of hMLH1 methylation in plasma DNA after chemotherapy predicts poor survival for ovarian cancer patients. Clin Cancer Res. 2004;10:4420-6.

88. Zeller C, Dai W, Steele NL, Siddiq A, Walley AJ, Wilhelm-Benartzi CS, et al. Candidate DNA methylation drivers of acquired cisplatin resistance in ovarian cancer identified by methylome and expression profiling. Oncogene. 2012;31:4567-76.

89. Silver DP, Richardson AL, Eklund AC, Wang ZC, Szallasi Z, Li Q, et al. Efficacy of neoadjuvant Cisplatin in triple-negative breast cancer. J Clin Oncol. 2010;28:1145-53.

90. Colak S, Ten Dijke P. Targeting TGF-beta Signaling in Cancer. Trends Cancer. 2017;3:56-71.

91. Liu Q, Ma L, Jones T, Palomero L, Pujana MA, Martinez-Ruiz H, et al. Subjugation of TGFbeta signaling by human papilloma virus in head and neck squamous cell carcinoma shifts DNA repair from homologous recombination to alternative end joining. Clin Cancer Res. 2018;24:6001-14.

92. Zhang H, Xie C, Yue J, Jiang Z, Zhou R, Xie R, et al. Cancer-associated fibroblasts mediated chemoresistance by a FOXO1/TGFbeta1 signaling loop in esophageal squamous cell carcinoma. Mol Carcinog. 2017;56:1150-63.

93. Ashrafizadeh $M$, Zarrabi A, Hushmandi K, Kalantari M, Mohammadinejad R, Javaheri T, et al. Association of the epithelial-mesenchymal transition (EMT) with Cisplatin Resistance. Int J Mol Sci. 2020;21:4002.

94. Marchini S, Fruscio R, Clivio L, Beltrame L, Porcu L, Fuso Nerini I, et al. Resistance to platinum-based chemotherapy is associated with epithelial to mesenchymal transition in epithelial ovarian cancer. Eur J Cancer. 2013;49:520-30.

95. Wang J, Chen Y, Xiang F, Li M, Li H, Chi J, et al. Suppression of TGF-beta1 enhances chemosensitivity of cisplatin-resistant lung cancer cells through the inhibition of drug-resistant proteins. Artif Cells Nanomed Biotechnol. 2018;46:1505-12.

96. Pujade-Lauraine E, Banerjee S, Pignata S. Management of platinum-resistant, relapsed epithelial ovarian cancer and new drug perspectives. J Clin Oncol. 2019;37:2437-48

97. Shibue T, Weinberg RA. EMT, CSCs, and drug resistance: the mechanistic link and clinical implications. Nat Rev Clin Oncol. 2017;14:611-29.

98. Cancer Genome Atlas Research N. Integrated genomic analyses of ovarian carcinoma. Nature. 2011;474:609-15.

99. Prathapam T, Aleshin A, Guan Y, Gray JW, Martin GS. p27Kip1 mediates addiction of ovarian cancer cells to MYCC (c-MYC) and their dependence on MYC paralogs. J Biol Chem. 2010;285:32529-38.

100. Reyes-Gonzalez JM, Armaiz-Pena GN, Mangala LS, Valiyeva F, Ivan C, Pradeep S, et al. Targeting c-MYC in platinum-resistant ovarian cancer. Mol Cancer Ther. 2015;14:2260-9.

101. Hsieh AL, Walton ZE, Altman BJ, Stine ZE, Dang CV. MYC and metabolism on the path to cancer. Semin Cell Dev Biol. 2015;43:11-21.

102. Dang CV. MYC on the path to cancer. Cell. 2012;149:22-35.

103. Obrist F, Michels J, Durand S, Chery A, Pol J, Levesque S, et al. Metabolic vulnerability of cisplatin-resistant cancers. EMBO J. 2018:37:e98597.
104. Tramonti A, Nardella C, di Salvo ML, Barile A, Cutruzzola F, Contestabile R. Human cytosolic and mitochondrial serine hydroxymethyltransferase isoforms in comparison: full kinetic characterization and substrate inhibition properties. Biochemistry. 2018;57:6984-96.

105. Lawrence T. The nuclear factor NF-kappaB pathway in inflammation. Cold Spring Harb Perspect Biol. 2009;1:a001651.

106. Annunziata CM, Stavnes HT, Kleinberg L, Berner A, Hernandez LF, Birrer MJ, et al. Nuclear factor kappaB transcription factors are coexpressed and convey a poor outcome in ovarian cancer. Cancer. 2010;116:3276-84.

107. Godwin P, Baird AM, Heavey S, Barr MP, O'Byrne KJ, Gately K. Targeting nuclear factor-kappa B to overcome resistance to chemotherapy. Front Oncol. 2013;3:120.

108. Lagunas VM, Melendez-Zajgla J. Nuclear Factor-kappa B as a resistance factor to platinum-based antineoplasic drugs. Met Based Drugs. 2008;2008:576104.

109. Martindale JL, Holbrook NJ. Cellular response to oxidative stress: signaling for suicide and survival. J Cell Physiol. 2002;192:1-15.

110. Valencia T, Kim JY, Abu-Baker S, Moscat-Pardos J, Ahn CS, Reina-Campos M, et al. Metabolic reprogramming of stromal fibroblasts through p62-mTORC1 signaling promotes inflammation and tumorigenesis. Cancer Cell. 2014;26:121-35.

111. Liu T, Zhang $L$, Joo D, Sun SC NF-kappaB signaling in inflammation. Signal Transduct Target Ther 2017;2.

112. Cruz JJ, Ocana A, Del Barco E, Pandiella A. Targeting receptor tyrosine kinases and their signal transduction routes in head and neck cancer. Ann Oncol. 2007;18:421-30.

113. Varoni EM, Lo Faro AF, Sharifi-Rad J, Iriti M. Anticancer Molecular Mechanisms of Resveratrol. Front Nutr. 2016;3:8.

114. Hayakawa J, Ohmichi M, Kurachi H, Kanda $Y$, Hisamoto $K$, Nishio $Y$, et al. Inhibition of BAD phosphorylation either at serine 112 via extracellular signalregulated protein kinase cascade or at serine 136 via Akt cascade sensitizes human ovarian cancer cells to cisplatin. Cancer Res. 2000;60:5988-94.

115. Dempke W, Voigt W, Grothey A, Hill BT, Schmoll HJ. Cisplatin resistance and oncogenes-a review. Anticancer Drugs. 2000;11:225-36.

116. Penzvalto Z, Lanczky A, Lenart J, Meggyeshazi N, Krenacs T, Szoboszlai N, et al. MEK1 is associated with carboplatin resistance and is a prognostic biomarker in epithelial ovarian cancer. BMC Cancer. 2014;14:837.

117. Giancotti FG, Ruoslahti E. Integrin signaling. Science. 1999;285:1028-32.

118. Nallanthighal S, Rada M, Heiserman JP, Cha J, Sage J, Zhou B, et al. Inhibition of collagen XI alpha 1-induced fatty acid oxidation triggers apoptotic cell death in cisplatin-resistant ovarian cancer. Cell Death Dis. 2020;11:258.

119. Yoshihara M, Kajiyama $H$, Yokoi A, Sugiyama M, Koya $Y$, Yamakita $Y$, et al. Ovarian cancer-associated mesothelial cells induce acquired platinumresistance in peritoneal metastasis via the FN1/Akt signaling pathway. Int J Cancer. 2020;146:2268-80.

120. Wu WJ, Wang Q, Zhang W, Li L. [Identification and prognostic value of differentially expressed proteins of patients with platinum resistance epithelial ovarian cancer in serum]. Zhonghua Fu Chan Ke Za Zhi. 2016;51:515-23.

121. Diaz Osterman CJ, Ozmadenci D, Kleinschmidt EG, Taylor KN, Barrie AM, Jiang S, et al. FAK activity sustains intrinsic and acquired ovarian cancer resistance to platinum chemotherapy. Elife. 2019;8:e47327.

122. Karin M, Lawrence T, Nizet V. Innate immunity gone awry: linking microbial infections to chronic inflammation and cancer. Cell. 2006;124:823-35.

123. Jones VS, Huang RY, Chen LP, Chen ZS, Fu L, Huang RP. Cytokines in cancer drug resistance: cues to new therapeutic strategies. Biochim Biophys Acta. 2016;1865:255-65.

124. Rawlings JS, Rosler KM, Harrison DA. The JAK/STAT signaling pathway. J Cell Sci. 2004:117:1281-3.

125. Sun CY, Nie J, Huang JP, Zheng GJ, Feng B. Targeting STAT3 inhibition to reverse cisplatin resistance. Biomed Pharmacother. 2019;117:109135.

126. Meng J, Liu K, Shao Y, Feng X, Ji Z, Chang B, et al. ID1 confers cancer cell chemoresistance through STAT3/ATF6-mediated induction of autophagy. Cell Death Dis. 2020;11:137

127. Wang W, Kryczek I, Dostal L, Lin H, Tan L, Zhao L, et al. Effector T cells abrogate stroma-mediated chemoresistance in ovarian. Cancer Cell. 2016;165:1092-105.

128. Legrier ME, Bieche I, Gaston J, Beurdeley A, Yvonnet V, Deas O, et al. Activation of IFN/STAT1 signalling predicts response to chemotherapy in oestrogen receptor-negative breast cancer. Br J Cancer. 2016;114:177-87.

129. Gregorc V, De Braud FG, De Pas TM, Scalamogna R, Citterio G, Milani A, et al. Phase I study of NGR-hTNF, a selective vascular targeting agent, in combination with cisplatin in refractory solid tumors. Clin Cancer Res. 2011;17:1964-72.

130. Trop-Steinberg S, Azar Y. AP-1 expression and its clinical relevance in immune disorders and cancer. Am J Med Sci. 2017;353:474-83.

131. Madamanchi NR, Li S, Patterson C, Runge MS. Reactive oxygen species regulate heat-shock protein 70 via the JAK/STAT pathway. Arterioscler Thromb Vasc Biol. 2001;21:321-6.

132. Deramaudt BM, Remy $P$, Abraham NG. Upregulation of human heme oxygenase gene expression by Ets-family proteins. J Cell Biochem. 1999;72:311-21. 
133. Matassa DS, Amoroso MR, Lu H, Avolio R, Arzeni D, Procaccini C, et al. Oxidative metabolism drives inflammation-induced platinum resistance in human ovarian cancer. Cell Death Differ. 2016;23:1542-54.

134. Liao Y, Wang J, Jaehnig EJ, Shi Z, Zhang B. WebGestalt 2019: gene set analysis toolkit with revamped Uls and APIs. Nucleic Acids Res. 2019;47:W199-W205.

135. Santos R, Ursu O, Gaulton A, Bento AP, Donadi RS, Bologa CG, et al. A comprehensive map of molecular drug targets. Nat Rev Drug Disco. 2017;16:19-34.

136. Sakai W, Swisher EM, Jacquemont C, Chandramohan KV, Couch FJ, Langdon SP et al. Functional restoration of BRCA2 protein by secondary BRCA2 mutations in BRCA2-mutated ovarian carcinoma. Cancer Res. 2009;69:6381-6.

137. Ai Z, Lu Y, Qiu S, Fan Z. Overcoming cisplatin resistance of ovarian cancer cells by targeting HIF-1-regulated cancer metabolism. Cancer Lett. 2016;373:36-44.

138. Li Z, Zhou W, Zhang Y, Sun W, Yung MMH, Sun J, et al. ERK regulates HIF1alphamediated platinum resistance by directly targeting PHD2 in ovarian cancer. Clin Cancer Res. 2019;25:5947-60.

139. Dai $Y$, Jin S, Li X, Wang D. The involvement of Bcl-2 family proteins in AKTregulated cell survival in cisplatin resistant epithelial ovarian cancer. Oncotarget. 2017;8:1354-68.

140. Stronach EA, Alfraidi A, Rama N, Datler C, Studd JB, Agarwal R, et al. HDAC4regulated STAT1 activation mediates platinum resistance in ovarian cancer. Cancer Res. 2011;71:4412-22.

141. Cooke SL, Ng CK, Melnyk N, Garcia MJ, Hardcastle T, Temple J, et al. Genomic analysis of genetic heterogeneity and evolution in high-grade serous ovarian carcinoma. Oncogene. 2010;29:4905-13.

142. Hermeking H, Eick D. Mediation of c-Myc-induced apoptosis by p53. Science. 1994;265:2091-3.

143. Chen R, Guo S, Yang C, Sun L, Zong B, Li K, et al. Although CMYC contributes to tamoxifen resistance, it improves cisplatin sensitivity in ERpositive breast cancer. Int J Oncol. 2020;56:932-44.

144. Liang X, Guo Y, Figg WD, Fojo AT, Mueller MD, Yu JJ. The role of wild-type p53 in cisplatin-induced Chk2 phosphorylation and the inhibition of platinum resistance with a Chk2 inhibitor. Chemother Res Pr. 2011;2011:715469.

145. Alkema NG, Tomar T, van der Zee AG, Everts M, Meersma GJ, Hollema $H$, et al. Checkpoint kinase 2 (Chk2) supports sensitivity to platinum-based treatment in high grade serous ovarian cancer. Gynecol Oncol. 2014;133:591-8.

146. Sarbia M, Ott N, Puhringer-Oppermann F, Brucher BL. The predictive value of molecular markers ( $\mathrm{p} 53, \mathrm{EGFR}, \mathrm{ATM}, \mathrm{CHK} 2$ ) in multimodally treated squamous cell carcinoma of the oesophagus. Br J Cancer. 2007;97:1404-8.

147. Santamaria G, Martinez-Diez M, Fabregat I, Cuezva JM. Efficient execution of cell death in non-glycolytic cells requires the generation of ROS controlled by the activity of mitochondrial H+-ATP synthase. Carcinogenesis. 2006;27:925-35.

148. Yamada M, Tomida A, Yoshikawa H, Taketani $Y$, Tsuruo T. Increased expression of thioredoxin/adult T-cell leukemia-derived factor in cisplatin-resistant human cancer cell lines. Clin Cancer Res. 1996;2:427-32.

149. Yokomizo A, Ono M, Nanri H, Makino Y, Ohga T, Wada $M$, et al. Cellular levels of thioredoxin associated with drug sensitivity to cisplatin, mitomycin $C$, doxorubicin, and etoposide. Cancer Res. 1995;55:4293-6.

\section{ACKNOWLEDGEMENTS}

This work was done in collaboration with the U.S. National Cancer Institute's Clinical Proteomic Tumor Analysis Consortium (CPTAC) and supported by grants
U01CA214114 (AGP, MJB), DOD W81XWH-16-2-0038 (MJB), U24CA210993 (PW) University of Minnesota Grand Challenges grant, Randy Shaver Cancer Research and Community Fund Grant and NIH NCI R21CA216652 (TKS), and Scientific Computing Infrastructure at Fred Hutch funded by ORIP grant S10OD028685.

\section{AUTHOR CONTRIBUTIONS}

$\mathrm{DH}$ and AGP conceived and designed the study; CL performed the MEDLINE database search of platinum resistance related genes and references. $\mathrm{DH}$ read the references and additional related papers to select and compile the platinum resistance related genes list; SRS and BZ performed statistical data analysis; APC and PW designed the online searchable database. Study was supervised by AGP, the paper was drafted by DH and TKS, and edited by BZ, PW, MJB and AGP.

\section{COMPETING INTERESTS}

MJB has participated in advisory boards for the following companies: Clovis, Astra Zeneca and GSK-Tesaro.

\section{ADDITIONAL INFORMATION}

Supplementary information The online version contains supplementary material available at https://doi.org/10.1038/s41388-021-02055-2.

Correspondence and requests for materials should be addressed to Amanda G. Paulovich.

Reprints and permission information is available at http://www.nature.com/ reprints

Publisher's note Springer Nature remains neutral with regard to jurisdictional claims in published maps and institutional affiliations.

\begin{abstract}
(c) (i)
Open Access This article is licensed under a Creative Commons Attribution 4.0 International License, which permits use, sharing adaptation, distribution and reproduction in any medium or format, as long as you give appropriate credit to the original author(s) and the source, provide a link to the Creative Commons license, and indicate if changes were made. The images or other third party material in this article are included in the article's Creative Commons license, unless indicated otherwise in a credit line to the material. If material is not included in the article's Creative Commons license and your intended use is not permitted by statutory regulation or exceeds the permitted use, you will need to obtain permission directly from the copyright holder. To view a copy of this license, visit http://creativecommons. org/licenses/by/4.0/.
\end{abstract}

(c) The Author(s) 2021 